\title{
EXPLORING THE UNDERGRADUATE WORLD OF ELECTRONIC SOCIAL NETWORKING: AN EXAMINATION OF ATTITUDE, ADOPTION, AND USAGE
}

\author{
Carl J. Case, St. Bonaventure University, ccase@sbu.edu \\ Darwin L. King, St. Bonaventure University, dking@sbu.edu
}

\begin{abstract}
Electronic social networking technologies are continuing to be driving forces in the business world. This study was undertaken to examine whether usage by college students is keeping pace. Results indicate that most undergraduates also believe that electronic social networking is either somewhat or very important to him/her. Moreover, this importance varies by gender and academic class. In addition, although not used by as many undergraduates as Facebook, Twitter is seeing dramatic growth within the student population and is highly utilized by those that have adopted the technology. As a result, faculty may find it increasingly challenging to maintain student focus during class time as faculty compete with these student handheld technologies. Moreover, there may be implications with regard to the IT infrastructure needed to support this escalating demand. Finally, there may be marketing opportunities with respect to undergraduate consumers as only $12 \%$ of students indicated receiving business tweets.
\end{abstract}

Keywords: Electronic Social Networking, Facebook, Twitter, Empirical Study

\section{INTRODUCTION}

Corporations are increasingly adopting social networking as a primary communication tool [12]. According to Gartner, by 2014, social networking services will replace electronic mail as the primary vehicle for interpersonal communication by as many as $20 \%$ of business users [18]. Social media skills have even been predicted as one of the information technology (IT) skills that will boost one's IT career in 2012 [5]. Social networking has also been identified as one of the five cores areas that is driving IT spending as worldwide IT spending is forecasted to grow by $3.7 \%$ and $56 \%$ of companies plan to spend more on IT in 2012 [15].

In 2009, only 42\% of InformationWeek 500 companies used wikis, blogs, or social networking tools to collaborate with customers, suppliers, and partners [13]. In 2011, 77\% of these companies used web 2.0 technologies. This adoption may be due in part to market forces. A 2011 Accenture survey of 10,000 consumers, for example, found that $24 \%$ are more likely to do business with a company that they can interact within a social media environment and $25 \%$ stated that social media comments influence their opinions about companies or brands [10].

There are, however, challenges with regard to social networking. Gartner, for example, predicts that $70 \%$ of ITdominated social initiatives will fail as IT professionals will struggle with shifting from providing a platform to delivering a solution [15]. In addition, an InformationWeek survey found that with regard to internal social networks, $25 \%$ stated that they are fair or poor, $37 \%$ average, $25 \%$ good, and $13 \%$ excellent [9]. The greatest obstacles identified are user adoption (35\% of respondents), time required to manage applications (17\%), increasing employee usage (16\%), and explaining the role of social networking as it applies to business (15\%). Moreover, a Forrester survey of 4,985 U.S. information workers published in the fall of 2011 found that only $28 \%$ of workers use any kind of social software at least monthly for work. Just $22 \%$ stated that the technology is vital to their jobs. The primary reasons cited for using social software at work is that it is easy to learn and fills a job need (39\% of respondents) and that it is the most efficient way to do their jobs (38\% of respondents). Finally, the research firm Corporate Executive Board survey of 53 companies in September 2010 found that user adoption of Enterprise 2.0 technologies lagged initial deployment by five to eight quarters [16].

Despite the challenges, organizations are implementing social networking systems. A Social Networking in the Enterprise Survey of 394 business technology professionals in October 2011 found that $87 \%$ have at least one form 


\section{Issues in Information Systems}

Volume 13, Issue 1, pp. 51-58, 2012

of internal social network [9]. Interestingly, in 54\% of companies, marketing has taken ownership of social network monitoring tools. The internal systems with moderate to heavy traffic include online company directories (53\% of organizations), team or company wikis (37\%), company discussion forums (30\%), internal blogs (28\%), and social bookmarking or tagging systems (23\%). At companies using one or more internal social networking systems, $66 \%$ use Facebook, 62\% utilize LinkedIn, and 53\% use Twitter [10].

Facebook is extremely popular with 845 million users worldwide in 2012 and 152 million users in the U.S., roughly one half of the U.S. population [10]. Levi Strauss, for example, gets more that one million visits per month on Facebook and has 6.2 million followers [4]. Of note, only 19\% of companies were reported to have an external presence on Facebook for more than two years.

Another product that has grown dramatically in adoption is Twitter. Twitter, launched in July 2006 and named by eWeek as one of the top 20 technologies that changed the decade, is the dominant microblogging social network service [6]. Twitter is based in San Francisco but is used by individuals in nearly every country in the world. Twitter is available in more than 20 languages such as English, French, German, Italian, Japanese, and Spanish [20]. ComScore estimates that Twitter.com attracted 139 million unique visitors worldwide in May, 2011, a 54\% annual increase, with 200 million tweets per day [19]. Twitter traffic was up 12.5\% attracting an estimated 27 million unique visitors in May, 2011. Twitter announced in August of 2011 that it had over 100 million active users worldwide, half of whom log in daily and $40 \%$ that had not tweeted in the prior month [1]. Twitter defines an "active user" as anyone who logs into Twitter once a month. According to a post on Google+ by FT tech and media reporter Tim Bradshaw (via Twitter's Rachel Bremer), Twitter also revealed that it was processing 230 million tweets a day, a $100 \%$ increase since the start of the year. In terms of demographics, a Pew Internet \& American Life Project July 2011 survey found that 16\% of individuals ages 12 to 17 use Twitter, an increase from 8\% in 2009 [11]. Moreover, one in five 18-29 year olds are using Twitter. As a result, Twitter has changed the business of celebrity endorsements. Companies have utilized celebrities such as Snoop Dogg, singer Jay J, Lamar Odoms, and Lindsay Lohan to market their products through tweets [17].

\section{PREVIOUS RESEARCH}

Previous research has examined different facets of electronic social networking. Researchers have studied implementation, usage, social influence factors, adoption, knowledge sharing, and desertion.

A 2009 study, for example, examined web pages of the Fortune 50 firms as listed on the CNN Money website to determine their implementation and usage of Twitter [3]. Results indicated that the majority, 54\%, of firms had a Twitter account. Moreover, $37 \%$ of these firms had multiple accounts. Although usage varied by industry sector, $85 \%$ of the companies utilizing Twitter used the technology for news distribution. Twitter was used to a much lesser extent for marketing/promotions, customer service, and human resources.

A similar study examined web pages at the Association to Advance Collegiate Schools of Business (AACSB) accredited schools of business to determine the implementation and usage of electronic social networking [2]. Results indicated that although 39\% of the AACSB accredited institutions utilized electronic social networking, they lagged behind business implementation in terms of percentage of organizations and number of technologies used per organization. Furthermore, only $34 \%$ of schools utilized two or more networking technologies. The primary products included Facebook, Twitter, YouTube, and LinkedIn. In terms of institutional control, private institutions were more likely to utilize a given technology and use more technologies per school than public institutions.

Another study empirically investigated the influence of social influence factors, technology acceptance factors, and demographic factors on instant message (IM) adoption in the workplace [8]. Researchers found that social influence (subjective norm and perceived critical mass combined) was found to be a more important factor in determining IM adoption than perceived usefulness and perceived ease of use. Gender and age did not impact the adoption of IM.

In terms of adoption, a multiple case study of wiki-based knowledge management systems found that knowledge management is a social activity and that system development teams with more diverse capabilities are more likely to 


\section{Issues in Information Systems}

Volume 13, Issue 1, pp. 51-58, 2012

create unique socio-technical systems that require different user attitudes and behavioral patterns toward organizational knowledge [14]. In addition, adoption should be supported by providing meaningful incentives, inbuilt assistance, and social interaction rather than a simple one-way transmission of information.

Virtual communities were also examined to determine if organizational citizenship behaviors and social capital influence knowledge-sharing [21]. A proposed model empirically analyzed 424 users of virtual communities. Results showed that social interaction ties and identification of social capital have a strong impact on members' knowledge-sharing intentions and knowledge quality. In addition, most of the organizational citizenship behavior dimensions of altruism and civic virtue have a significant impact on the facets of social capital.

Finally, a quasi-experimental research design was employed to study deadbeats and deserters in virtual teams [7]. Deadbeats and deserters reported experiencing more conflict and less trust, group cohesion, and satisfaction when working in virtual teams. Results showed that in terms of conflict management approaches, deserters were more likely to use an avoidance conflict management style than active members. Active members were more likely to use an integrative approach to conflict management, one that places a high regard on personal and team member concerns. Overall, results suggest that conflict and the way by which individuals deal with it may impact the likelihood of social loafing and desertion in virtual teams.

Given the recent publicity with regard to social networking and increased usage in the business world, this study was undertaken to better understand the state of social networking behavior of undergraduate students. Because students are the future contributors and users of these technologies, it is important to understand their behavior.

This research, therefore, examines several questions. How important is social networking to students? Does this viewpoint vary by gender or academic class? How much time is spent social networking and in particular, how much time do students utilize Facebook and Twitter, two premier social networking platforms? Have there been longitudinal changes in terms of participation? Is there a relationship between the type of activity and the student's perceived importance of social networking. Finally, do students feel addicted? Results are important in helping institutions of higher learning to better understand social network technology implications and to assist in identifying potential usage opportunities.

\section{RESEARCH DESIGN}

This study employs a survey research design. The research was conducted at a private northeastern U.S. university. A Student Social Networking Behavior survey instrument was developed and administered during a fiveconsecutive semester period (Fall 2009, Spring 2010, Fall 2010, Spring 2011, and Fall 2011) to undergraduate students enrolled in a School of Business course. The sample had a $100 \%$ response rate and included a variety of courses such as BIS-310 "Business Information Systems", BIS-320 "Business Telecommunications", BIS-335 "System Analysis and Design", ACCT-201 "Introduction to Financial Accounting”, ACCT-202 "Introduction to Managerial Accounting”, and MSC-413 "Business Policy.” A convenience sample of class sections was selected in order to maximize student participation. The class sections were conducted by a variety of faculty.

The survey instrument was utilized to collect student demographic data and examine student behavior with regard to electronic social networking. Respondents were prompted to identify the degree of importance that social sites are to him/her. In addition, the survey requested that each student estimate the number of hours per week that he/she visited social sites, sent tweets, and received tweets. Finally, respondents were asked to quantify the amount of tweets sent/received and the number of accounts that he/she follow. The survey was administered during the final week of each of the 15-week semesters and all surveys were anonymous. Moreover, students were informed that results would have no effect on their semester grade. 


\section{Issues in Information Systems}

Volume 13, Issue 1, pp. 51-58, 2012

\section{RESULTS}

A sample of 897 usable surveys was obtained. Sixty percent of the respondents were male and $40 \%$ were female (Table1). In terms of academic class, $18 \%$ of the respondents were freshmen, $43 \%$ were sophomores, $21 \%$ were juniors, and 18\% were seniors (Table 2).

Table 1. Response Rate By Gender

\begin{tabular}{||c|r|r||}
\hline Gender & \multicolumn{1}{|c|}{ Count } & \multicolumn{1}{c|}{ Percentage } \\
\hline \hline Male & 539 & $60 \%$ \\
\hline Female & 358 & $40 \%$ \\
\hline Total & 897 & $100 \%$ \\
\hline
\end{tabular}

Table 2. Response Rate By Academic Class

\begin{tabular}{||l|r||}
\hline \multicolumn{1}{|c|}{ Class } & Percentage \\
\hline \hline Freshmen & $18 \%$ \\
\hline Sophomore & $43 \%$ \\
\hline Junior & $21 \%$ \\
\hline Senior & $18 \%$ \\
\hline
\end{tabular}

Undergraduates were first prompted to indicate the level of importance that social sites are to him/her (Table 3). With respect to males, $27 \%$ feel that social sites are not important, $47 \%$ indicate that social sites are somewhat important, and $12 \%$ feel that social sites are very important. Females, on the other hand, indicated a higher importance with 55\% feeling that social sites are somewhat important and 18\% indicating that social sites are very important. In terms of academic class, level of importance also varied (Table 4). With regard to freshmen, 19\% indicate that social sites are not important while $25 \%$ feel that social sites are very important. With respect to sophomores, $22 \%$ indicate that social sites are not important while $15 \%$ feel that social sites are very important. With regard to juniors, $29 \%$ feel that social sites are not important while $10 \%$ feel that social sites are very important. With respect to seniors, $27 \%$ feel that social sites are not important while $10 \%$ feel that social sites are very important.

Table 3. Importance of Social Sites by Gender

\begin{tabular}{||l|r|r|r|r||}
\hline \multicolumn{1}{|c|}{ Gender } & Not & Somewhat & \multicolumn{1}{c|}{ Very } & \multicolumn{1}{c|}{$\begin{array}{c}\text { No } \\
\text { Response }\end{array}$} \\
\hline \hline Male & $27 \%$ & $47 \%$ & $12 \%$ & $14 \%$ \\
\hline Female & $19 \%$ & $55 \%$ & $18 \%$ & $8 \%$ \\
\hline \hline Overall & $24 \%$ & $50 \%$ & $15 \%$ & $11 \%$ \\
\hline
\end{tabular}




\section{Issues in Information Systems}

Volume 13, Issue 1, pp. 51-58, 2012

Table 4. Importance of Social Sites by Academic Class

\begin{tabular}{||l|r|r|r|r||}
\hline \hline Academic Class & \multicolumn{1}{c|}{ Not } & \multicolumn{1}{c|}{ Somewhat } & \multicolumn{1}{c|}{ Very } & \multicolumn{1}{c|}{$\begin{array}{c}\text { No } \\
\text { Response }\end{array}$} \\
\hline \hline Freshman & $19 \%$ & $47 \%$ & $25 \%$ & $9 \%$ \\
\hline Sophomore & $22 \%$ & $54 \%$ & $15 \%$ & $9 \%$ \\
\hline Junior & $29 \%$ & $48 \%$ & $10 \%$ & $13 \%$ \\
\hline Senior & $27 \%$ & $46 \%$ & $10 \%$ & $14 \%$ \\
\hline \hline \multicolumn{1}{|c|}{ Overall } & $24 \%$ & $50 \%$ & $15 \%$ & $11 \%$ \\
\hline \hline
\end{tabular}

To examine behavior, each student was requested to estimate the number of hours per week that he/she visited social sites. Relative to academic class, $94 \%$ of freshmen, $91 \%$ of sophomores, $87 \%$ of juniors, and $89 \%$ of seniors reported visiting social sites (Table 5). In terms of social site visit time, freshmen spent 20.2 hours per week, sophomores spent 15.7 hours per week, juniors spent 10.6 hours per week, and seniors spent 15.4 hours per week.

Table 5. E-Socializing by Academic Class

\begin{tabular}{||l|r|r|r|r||}
\hline \multicolumn{1}{|c|}{ Activity } & Freshmen & \multicolumn{1}{c|}{ Sophomores } & \multicolumn{1}{c|}{ Juniors } & \multicolumn{1}{c|}{ Seniors } \\
\hline \hline Visit social sites & $94 \%$ & $91 \%$ & $87 \%$ & $89 \%$ \\
\hline Hours per week visiting social sites & 20.2 & 15.7 & 10.6 & 15.4 \\
\hline \hline
\end{tabular}

The study next examined behavior with respect to Facebook and Twitter, two of the predominate social networking technologies. Table 6 details the activity, number of hours per week, and quantity of various types of tweets per week. Results show that students who visit Facebook spend an average of 15.3 hours per week. In terms of Twitter, students spend 11.7 hours sending tweets (an average of 204 tweets) and 13.1 hours receiving tweets (an average of 554 tweets) per week. Moreover, students indicate receiving an average of 48 business tweets per week. There were, however, no significant differences in academic class for any type of Twitter behavior. When examining student perception of social site importance with activity type, there is a correlation significant at the .01 level with regard to visiting Facebook. There were no other significant correlations.

Table 6. E-Socializing by Type

\begin{tabular}{|c|c|c|c|c|}
\hline Activity & $\begin{array}{l}\text { Hours Per } \\
\text { Week }\end{array}$ & $\begin{array}{c}\text { Quantity Per } \\
\text { Week }\end{array}$ & $\begin{array}{c}\text { Chi- } \\
\text { Square } \\
\text { Class } \\
\text { Differences } \\
\end{array}$ & $\begin{array}{c}\text { Pearson } \\
\text { Correlation } \\
\text { with } \\
\text { Importance } \\
\end{array}$ \\
\hline Visit Facebook & 15.3 & & & $.096 *$ \\
\hline Send tweets & 11.7 & 204 & .028 & -.015 \\
\hline Receive tweets & 13.1 & 554 & .053 & -.012 \\
\hline Receive business tweets & & 48 & .031 & .038 \\
\hline
\end{tabular}

* Significant at the .01 level 


\section{Issues in Information Systems}

Volume 13, Issue 1, pp. 51-58, 2012

Table 7 depicts electronic social networking behavior longitudinally. During the Fall 2009 semester, 100\% of students indicated using Facebook, 11\% used Twitter, and 3\% received business tweets. By the Fall 2011 semester, 98\% of students indicated using Facebook, 43\% used Twitter, and 12\% received business tweets.

Table 7. Adoption By Semester

\begin{tabular}{||l|r|r|r|r|r||}
\hline \multicolumn{1}{|c|}{ Activity } & $\begin{array}{c}\text { Fall } \\
\mathbf{2 0 0 9}\end{array}$ & $\begin{array}{c}\text { Spring } \\
\mathbf{2 0 1 0}\end{array}$ & $\begin{array}{c}\text { Fall } \\
\mathbf{2 0 1 0}\end{array}$ & $\begin{array}{c}\text { Spring } \\
\mathbf{2 0 1 1}\end{array}$ & $\begin{array}{c}\text { Fall } \\
\mathbf{2 0 1 1}\end{array}$ \\
\hline \hline Facebook & $100 \%$ & $91 \%$ & $93 \%$ & $94 \%$ & $98 \%$ \\
\hline Twitter & $11 \%$ & $6 \%$ & $12 \%$ & $38 \%$ & $43 \%$ \\
\hline Receive business tweets & $3 \%$ & $2 \%$ & $7 \%$ & $16 \%$ & $12 \%$ \\
\hline \hline
\end{tabular}

In terms of gender, $88 \%$ of males and $94 \%$ of females indicated visiting social sites (Table 8 ). When examining addiction, only $3 \%$ of males and $4 \%$ of females felt addicted to Twitter.

Table 8. Gender Differences

\begin{tabular}{||c|r|r||}
\hline \multicolumn{1}{|c|}{ Activity } & \multicolumn{1}{c|}{ Male } & \multicolumn{1}{c|}{ Female } \\
\hline \hline Visit social sites & $88 \%$ & $94 \%$ \\
\hline Addicted to Twitter & $3 \%$ & $4 \%$ \\
\hline
\end{tabular}

Finally, undergraduates were prompted to indicate the type and quantity of individuals that he/she follow on Twitter. Respondents follow an average of 50 friends/family and 31 celebrities (Table 9).

Table 9. Individuals Followed

\begin{tabular}{||l|r||}
\hline Who Followed & $\begin{array}{c}\text { Number } \\
\text { Followed Per } \\
\text { Respondent }\end{array}$ \\
\hline \hline Friends/family & 50 \\
\hline Celebrities & 31 \\
\hline
\end{tabular}

\section{CONCLUSIONS, IMPLICATIONS, AND FUTURE RESEARCH}

Results show 65\% of undergraduates feel that social networking is either somewhat or very important to them. A much larger percentage of females versus males, $18 \%$ versus $12 \%$, however, indicate that social networking is very important. Within each academic class, roughly one-half of the undergraduates feel that social sites are somewhat important to them. Although $25 \%$ of freshmen indicated that social sites are very important to them, only $10 \%$ of seniors, however, feel that social networking is very important.

In terms of behavior, social networking is common. Nine of every 10 students indicate visiting social sites. Each week, freshmen spend 20.2 hours, sophomores spend 15.7 hours, juniors spend 10.6 hours, and seniors spend 15.4 hours visiting social sites.

Facebook usage is noteworthy and consistent with usage identified in the general population by previous research. Nearly all students indicate using Facebook, for an average of more than 2 hours per day or 15.3 hours per week per student. The use of Facebook was statistically related to the student's indication of electronic social networking importance. 


\section{Issues in Information Systems}

Volume 13, Issue 1, pp. 51-58, 2012

This study also found that Twitter usage is not nearly as common as Facebook usage in terms of the percentage of students. It is, none the less, impressive in terms of usage hours and participation growth. Students indicate spending 11.7 hours per week sending tweets (204 tweets per week) and 13.1 hours receiving tweets (554 per week). However, only 48 business tweets are received each week. There were no statistically significant relationships between Twitter usage and either academic class or social site importance. In terms of who is followed, students follow an average of 50 friends/family and 31 celebrities.

From a longitudinal perspective, while only 11\% of students used Twitter in Fall 2009, 43\% indicated using Twitter in Fall 2011, a four-fold increase. In addition, the percentage of students receiving business tweets increased from $3 \%$ to $12 \%$ during the same five-semester period. Facebook adoption remained relatively stable.

Finally, results suggest that a greater percentage of females use social network sites than males, $94 \%$ versus $88 \%$, respectively. In addition, more females indicated being addicted to Twitter than males, $4 \%$ versus $3 \%$, respectively.

\section{Implications}

There are four important implications as a result of these findings:

1. One implication is that gender and academic class are factors with regard to social networking. A higher percentage of females, relative to males, indicate that social networking is important to them. Moreover, a higher percentage of freshmen, relative to seniors, indicate that social networking is important to them. In terms of time, freshmen also indicate that they spend more time visiting social sites than any other academic class. As a result, marketers may wish to direct efforts more with regard to females, and in particular, younger females.

2. A second implication is that although Twitter is not used by as many undergraduates as Facebook, it is seeing tremendous growth with respect to the number of students adopting the technology. From Fall 2009 to Fall 2010, Twitter usage increased nearly $300 \%$ from $11 \%$ of students to $43 \%$ of students. Moreover, Twitter is highly used by those that have adopted the technology. While Facebook users indicate usage of 15.3 hours per week, Twitter users spend 24.8 hours per week sending and receiving tweets. In addition, $4 \%$ of females and $3 \%$ of males feel that they are addicted to Twitter. As a result of this dramatic growth in Twitter usage among students and the temptation to monitor Twitter feeds, faculty may find it increasingly difficult to maintain student interest and focus during class time. Moreover, this usage may put further demands upon the university's IT infrastructure.

3. A third implication is that with regard to Twitter, there may be marketing opportunities with respect to undergraduate consumers. Only $12 \%$ of students indicated receiving business tweets (an average of 48, or $9 \%$ of all tweets received) per week. Although marketers are utilizing celebrities, those targeting students may be increasingly important and effective as the adoption rate of Twitter increases.

4. A fourth implication is that given the pervasive use of social networking technologies by students, there may be further academic opportunities available. Facebook, for example, may be a mechanism for better establishing relationships between students seeking employment and alumni in the workforce. In addition, as the adoption of Twitter continues to climb, the role and importance of Twitter will probably grow and evolve for institutions of higher learning. Schools will likely find that Twitter is an increasing effective mechanism for news distribution, emergency notifications, and marketing to prospective students, current students, and graduates.

The limitations of this study are primarily a function of sample size, sample distribution, and type of research. A larger sample size, more equal distribution among academic class and gender, and use of additional universities would increase the robustness of results. Another limitation relates to the self-reported nature of the survey. Finally, addiction is not clinically defined in the survey instrument so student perception may be open to 


\section{Issues in Information Systems}

Volume 13, Issue 1, pp. 51-58, 2012

interpretation. Future studies with a larger sample size and a different research methodology would yield data that is beneficial and would expand this study. Overall, findings of this study will help to provide a better understanding of student electronic social behavior in order to inform business, academic, IT, and marketing practices.

\section{REFERENCES}

1. Bosker, B. (2011). Twitter Finally Shares Key Stats: 40 Percent of Active Users Are Lurkers. Huffingtonpost.com. November. Available: http://www.huffingtonpost.com/2011/09/08/twitterstats_n_954121.html

2. Case, C. J. \& D. L. King (2011). AACSB Accredited Institutions and the Web 2.0: Lagging Behind Businesses in Social Networking Implementation. Issues in Information Systems. Volume XII(2), 1-8.

3. Case, C. J. \& D. L. King (2011). Twitter Usage in the Fortune 50: A Marketing Opportunity? Journal of Marketing Development and Competitiveness. 5.3, 94-103.

4. Claburn, T. (2012). For Clothing Maker, Social Media's A Perfect Fit. Informationweek.com, 1309, 27-28.

5. Doyle, K. (2011). Six Skills That Will Boost Your IT Career In 2012. Globalknowledge.com. December. Available: http://www.globalknowledge.com/articles/generic.asp?pageid=3138\&country=United+States

6. eWeek Lab Staff (2010). 25 Technologies That Changed The Decade. eweek, 27(3), 18-24.

7. Furumo, K. (2009). The Impact of Conflict and Conflict Management Style on Deadbeats and Deserters in Virtual Teams. Journal of Computer Information Systems. 49(4), 66-73.

8. Glass, R. \& Li, S. (2010). Social Influence and Instant Message Adoption. Journal of Computer Information Systems. 51(2), 24-30.

9. Healey, M. (2012). Dislike. Informationweek.com, 1322, 19-25.

10. Henschen, D. (2012). From CRM To Social. Informationweek.com, 1325, 16-20.

11. Irving, M. (2012). Teens Migrating To Twitter. The Times Herald, January 30, B-8.

12. Muller, R. (2011). Seven Technology Predictions For 2012. Globalknowledge.com. November. Available: http://www.globalknowledge.com/articles/generic.asp?pageid=3129\&country=United+States

13. Murphy, C. (2011). 500: Focused, and Better Funded. Informationweek.com, 1309, 13-18.

14. Pfaff, C. C. \& Hasan, H. (2011). Wiki-Based Knowledge Management Systems For More Democratic Organizations. Journal of Computer Information systems, 52(2), 73-82.

15. Preston, R. (2012). Down To Business: 5 Core Areas That Will Drive This Year's IT Spending. Informationweek.com, 1321, 7-8.

16. Preston, R. (2011). Top CIO Priorities--And Perspective From India. Informationweek.com, 1314, 8-13.

17. Rexrode, C. (2011). Twitter Changes Business of Endorsements By Celebrities. The Times Herald, November 4, B-9.

18. Sarrel, M. (2010). Tapping The Positive From Social Networks For Collaboration. eweek, 27(20), 22-26.

19. Schonfeld, E. (2011). Twitter Reaches 200 Million Tweets A Day, But How Many Come From Bots? Available: http://techcrunch.com/2011/06/30/twitter-3200-million-tweets/

20. Twitter. (2012). About, Twitter.com. Available: http://twitter.com/about

21. Yoon, C. \& Wang, Z. (2011). The Role of Citizenship Behaviors and Social Capital in Virtual Communities. Journal of Computer Information Systems. 52(1), 